\title{
8
}
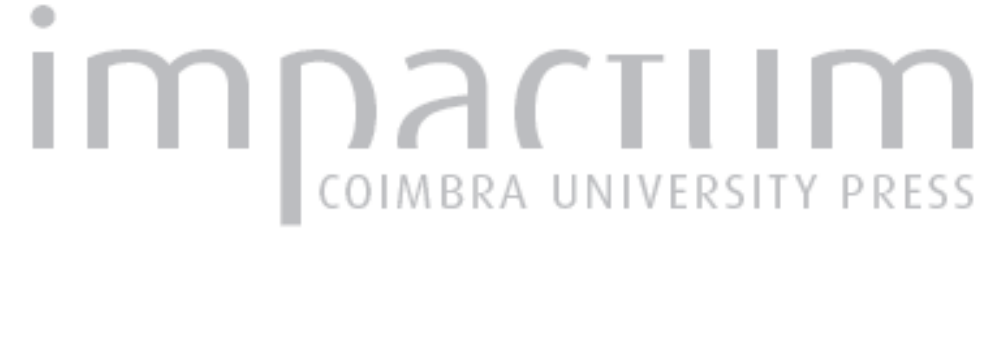

\section{Articulações entre verdade e subjectividade nos últimos estudos de Michel Foucaul: sobre a separação entre verdade e espiritualidade}

Autor(es): $\quad$ Galantin, Daniel Verginelli Publicado por: $\begin{aligned} & \text { Universidade Católica de Petrópolis; Instituto Brasileiro de Informação } \\ & \text { em Ciência e Tecnologia }\end{aligned}$

URL

persistente:

DOI: $\quad$ DOI:http://dx.doi.org/10.14195/1984-6754_4-1_1

Accessed : $\quad$ 26-Apr-2023 10:48:43

A navegação consulta e descarregamento dos títulos inseridos nas Bibliotecas Digitais UC Digitalis, UC Pombalina e UC Impactum, pressupõem a aceitação plena e sem reservas dos Termos e Condições de Uso destas Bibliotecas Digitais, disponíveis em https://digitalis.uc.pt/pt-pt/termos.

Conforme exposto nos referidos Termos e Condições de Uso, o descarregamento de títulos de acesso restrito requer uma licença válida de autorização devendo o utilizador aceder ao(s) documento(s) a partir de um endereço de IP da instituição detentora da supramencionada licença.

Ao utilizador é apenas permitido o descarregamento para uso pessoal, pelo que o emprego do(s) título(s) descarregado(s) para outro fim, designadamente comercial, carece de autorização do respetivo autor ou editor da obra.

Na medida em que todas as obras da UC Digitalis se encontram protegidas pelo Código do Direito de Autor e Direitos Conexos e demais legislação aplicável, toda a cópia, parcial ou total, deste documento, nos casos em que é legalmente admitida, deverá conter ou fazer-se acompanhar por este aviso. 

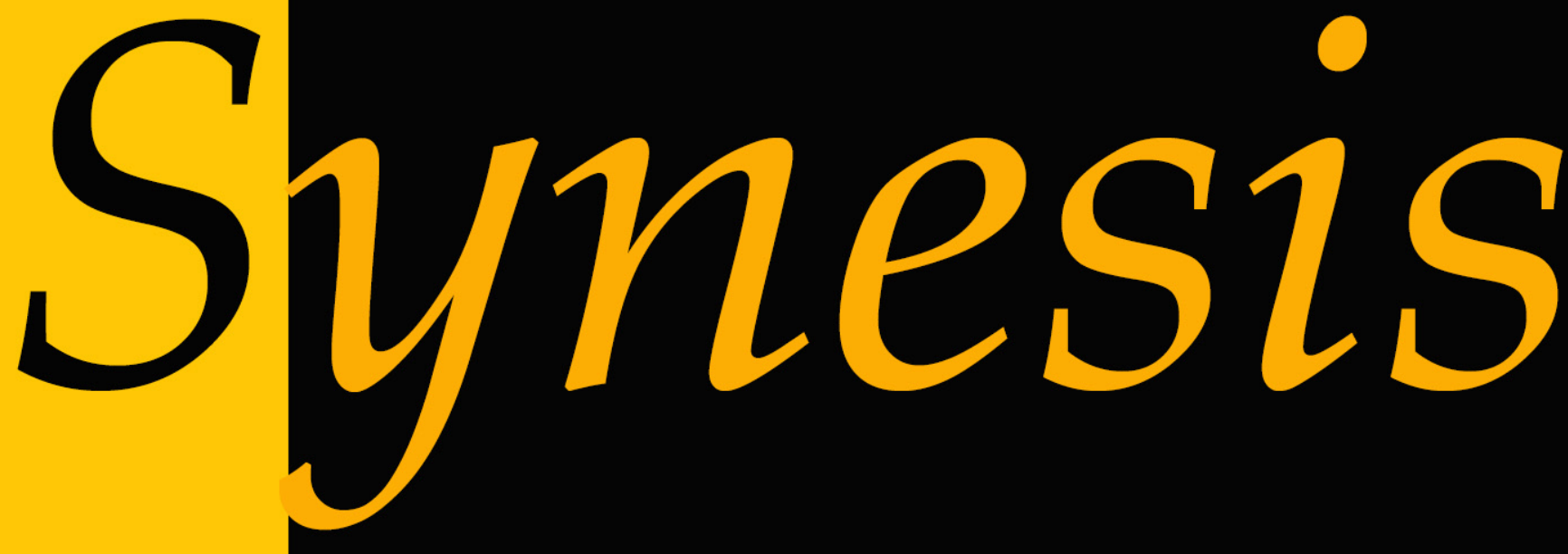

Revista do Centro de Teologia e Humanidades ISSN 1984-6754

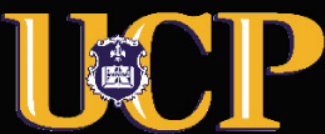




\title{
ARTICULAÇÕES ENTRE VERDADE E SUBJETIVIDADE NOS ÚLTIMOS ESTUDOS DE MICHEL FOUCAULT: SOBRE A SEPARAÇÃO ENTRE VERDADE E ESPIRITUALIDADE ${ }^{1}$
}

\author{
Daniel Verginelli Galantin ${ }^{2}$
}

Resumo: Neste artigo apresentamos algumas características concernentes à vinculação entre verdade e subjetividade nos estudos de Michel Foucault realizados durante a década de 1980. Para isso, iniciamos com uma breve introdução onde apresentamos o novo eixo das pesquisas de nosso autor, as técnicas de si. Em seguida nos concentramos em algumas aulas do curso Hermenêutica do Sujeito, onde Foucault aponta para uma separação entre filosofia e espiritualidade no decorrer da história da filosofia, separação que tem como marco a emergência da teologia. Após fazermos uma breve contraposição entre o modo como se articulam verdade e sujeito nos estudos de Foucault (realizados na década de 1970) sobre a época moderna, em comparação com as filosofias clássicas e helênicas, defendemos que tal separação entre filosofia e espiritualidade pode ser tomada como um dos pontos significativos a partir dos quais podemos entender a articulação entre verdade e subjetividade nos últimos estudos de Foucault, assim como suas implicações políticas.

Palvras-chave: Filosofia; espiritualidade; ética; subjetividade.

\begin{abstract}
In this article our goal is to present some of the characteristics which concern the vinculation between truth and subjectivity on Michel Foucault's 1980 research. So we begin by a short introduction where it's presented the new axis of our author's work, the technics of the self. After that we focus in some of the classes from Hermenentics of the Subject on which Foucault points out a separation between philosophy and spirituality in the middle of the history of philosophy; that separation is due to the emergence of theology. After a quick contraposition between the way which truth and subject are articulated on Foucault's studies on modernity (made on the 1970's), and the way they are articulated on classic and hellenic philosophies, we defend that such separation between truth and spirituality may be taken as a significant point by which we can understand the articulation between truth and subjectivity on Foucault's late work and their political implications.
\end{abstract}

Keywords: Philosophy; spirituality; ethics; subjectivity.

\footnotetext{
1 Artigo recebido em 30/01/2012 e aprovado para publicação pelo Conselho Editorial em 10/06/2012.

${ }^{2}$ Mestrando em Filosofia da Universidade Federal do Paraná. Currículo Lattes: http://lattes.cnpq.br/ 3881064026467115. E-mail: d.galantin@gmail.com.
} 


\section{Deslocamento para o estudo das técnicas de si durante a década de $\mathbf{1 9 8 0}$}

Se compararmos os estudos que Michel Foucault realizou na década de 1980 com aqueles da década de 1970, encontraremos uma série de deslocamentos significativos. Nos últimos foram estudadas as articulações entre poderes e saberes em suas transformações históricas, articulações que fazem aparecer novos objetos, e especialmente novos sujeitos. A partir dos anos 80, Foucault desloca seu olhar para a Grécia clássica (por volta do século IV a.C.), o período helênico-romano (séculos I e II d.C.), e, em menor escala, os primeiros cristãos $^{3}$ (IV e V d.C.). Entre os oito anos que separam a publicação dos dois primeiros volumes de "História da Sexualidade", Foucault dedicou-se a estudar as técnicas através das quais os indivíduos se constituem a si mesmos enquanto sujeitos éticos a partir de relações de si para consigo e com os outros: as práticas ou técnicas de si. Portanto, trata-se de um deslocamento ao mesmo tempo cronológico e temático.

No prefácio aos volumes II e III de "História da sexualidade", Foucault detalha o deslocamento que implicou na abertura de um novo eixo em suas pesquisas: "a fim de analisar o que é designado como 'o sujeito'; convinha pesquisar quais são as formas e as modalidades da relação consigo através das quais o indivíduo se constitui e se reconhece como sujeito" (FOUCAULT, 2010c, p.12). O acréscimo do estudo das diferentes formas de relação de si para consigo implicou na abertura de uma nova perspectiva também com relação aos jogos de verdade. Após estudar os jogos de verdade considerados entre si (arqueologia), e considerados em sua articulação com técnicas de poderes (genealogia), foi necessário "estudar os jogos de verdade na relação de si para si e a constituição de si mesmo como sujeito, tomando como espaço de referência e campo de investigação aquilo que poderia chamar-se 'história do homem de desejo". Em nome da historicização dos jogos de verdade Foucault opera este deslocamento e revê todo seu percurso filosófico a partir do novo eixo ao interrogar:

Através de quais jogos de verdade o homem se dá seu ser próprio a pensar quando se percebe como louco, quando se olha como doente, quando reflete sobre si como ser vivo, ser falante, ser trabalhador, quando se julga e

\footnotetext{
${ }^{3} \mathrm{Na}$ verdade Foucualt já havia se deparado com as tecnologias de poder cristãs desde seus estudos sobre o poder disciplinar, embora naquele momento se tratasse do medievo. Em "Vigiar e Punir", por exemplo, nosso autor deixa claro que, apesar da ruptura e da especificidade do investimento político sobre corpo ocorrido entre os séculos XVII e XVIII, as maneiras de enclausuramento e controle das atividades dos homens deste período têm uma proveniência monástica-cristã, sendo apropriadas para finalidades laicas (FOUCAULT, 2006b, pp.120-121; 123). Em 1978, durante o curso "Segurança, Território, População", após uma revisão de sua concepção de poder agora entendida enquanto governamentalidade ou modos de condução de condutas, nosso autor investigou especificamente as tecnologias de poder cristãs, as quais são concebidas pelo termo "poder pastoral" (FOUCAULT, 2008).
} 
se pune enquanto criminoso? Através de quais jogos de verdade o ser humano se reconheceu como homem de desejo? (FOUCUALT, 2010c, p.13) $)^{4}$.

Entendemos que a quantidade significativa de orações construídas na forma passiva e reflexiva seja um indício de que este sujeito não pode ser considerado o sujeito soberano das filosofias do sujeito, e nem o sujeito assujeitado, constituído no campo de imanência das articulações entre saberes e poderes (pois ele se constitui e se reconbece). Trata-se de outra abordagem do sujeito (assim como de outra abordagem da verdade), não mais como constituinte (como nas filosofias que o abordam através do ego transcendental) e nem como constituído (caráter ressaltado pelos estudos de Foucault até a década de $1970^{5}$ ); daí a torção e certa imprecisão nas palavras, como se Foucault tentasse fazê-las dizer mais que seu significado usual.

Desde suas investigações arqueológicas o filósofo francês apresenta uma concepção de verdade eminentemente histórica, a qual deslocou-se com o desenvolvimento de suas pesquisas referentes à sua articulação com poderes e, posteriormente, quanto à sua capacidade de transformar a relação que os sujeitos têm de si para consigo mesmos e com os outros. De modo que, no prefácio de "O uso dos prazeres", Foucault traça uma linha que ligaria os seus estudos, desde o desenvolvimento da arqueologia dos saberes até a genealogia da ética; pois ao se deparar com elementos de continuidade entre a hermenêutica de si cristã e a sexualidade moderna, é em nome de uma "história da verdade" que ele decide por alterar os planos originais de publicação da "História da Sexualidade":

E foi por este último partido que optei ao pensar que, afinal de contas, aquilo a que me atenho - a que me ative desde tantos anos - é a tarefa de evidenciar alguns elementos que possam servir para uma história da verdade. Uma história que não seja aquela do que poderia haver de verdadeiro nos conhecimentos; mas uma análise dos 'jogos de verdade', dos jogos entre o

\footnotetext{
${ }_{4}$ Podemos perceber como Foucault se refere aos seus trabalhos anteriores: História da Loucura, Nascimento da Clínica, As Palavras de as Coisas, Vigiar e Punir, História da Sexualidade respectivamente. No entanto este olhar retrospectivo serve antes para entendermos a especificidade do momento no qual ele é lançado (as pesquisas da década de 1980), que para entendermos as obras às quais ele se refere. Caso contrário, estaríamos adotando uma concepção de história anti-foucaultiana para os próprios trabalhos de Foucault, na medida em que projetaríamos retrospectivamente o presente da década de 1980 nos estudos das décadas de 1960 e 1970 . O risco desta abordagem da qual nos afastamos é marcar a obra de Foucault pela continuidade e latência de elementos que apenas progrediriam com o tempo. Não queremos dizer com isso que o problema da ética está completamente ausente de todas as suas obras anteriores, mas apenas que nelas o problema central não seria este, que ele não tem o mesmo peso que aquele dado pela retrospecção mencionada.

${ }^{5}$ Cabe ressaltar que a figura do sujeito enquanto constituído é o aspecto sob o qual Foucault se concentra na referida época, mas não se trata de seu único aspecto. Os sujeitos não eram considerados apenas constituídos na medida em que não existem relações de poder sem que hajam resistências, ou seja, não há sujeição sem resistência ao mecanismo de sujeição (FOUCAULT, 2010b, pp.105-107). Mas o problema das resistências é precisamente um dos que o levaram ao redirecionamento de seus estudos para as práticas de si (CANDIOTTO, 2010, pp.8592); (DELEUZE, 2009, pp.122-123).
} 
verdadeiro e o falso, através dos quais o ser se constitui historicamente como experiência, isto é, como podendo e devendo ser pensado (FOUCAULT, 2010c, p.13).

Se o ser se constitui historicamente enquanto experiência, Foucault concebe por experiência a correlação entre três eixos: práticas discursivas, práticas de poder, e práticas ou técnicas de si. No caso da sexualidade temos o maior exemplo quando Foucault a concebe enquanto experiência “(...) se entendemos por experiência a correlação, em uma cultura, entre campos do saber, tipos de normatividade e formas de subjetividade" (FOUCAULT, 2010c, p.10). Ou seja, trata-se da articulação histórica entre os três eixos referidos.

Quanto ao primeiro eixo, o do saber (ou práticas discursivas), Foucault tratou de investigar não como a verdade oculta aparece com o desenvolvimento de novas ciências ou de aparelhos de medição. Trata-se de desconstruir a idéia de progresso do saber (descoberta cumulativa de verdades ou mudança de paradigmas) para procurar os pontos de ruptura entre saberes normalmente concebidos enquanto desenvolvimento de conhecimentos anteriores (a história natural do XVIII e a biologia do XIX, por exemplo), assim como de encontrar seu isomorfismo com relação a saberes distintos na mesma época (a biologia, a filologia e a economia política, por exemplo). A partir do estudo de tal isomorfismo seria possível delimitar as regras de formação dos enunciados verdadeiros referentes a um determinado período. Numa entrevista realizada em 1977, Foucault resume o modo como ele problematiza as transformações nas práticas discursivas (em linhas gerais, trata-se do método arqueológico):

\footnotetext{
o importante em tais mudanças não é se elas serão rápidas ou de grande amplitude, ou melhor, tal rapidez e tal amplitude são sinais de outras coisas: uma modificação das regras de formação dos enunciados que são aceitos como cientificamente verdadeiros. Logo, não se trata de uma mudança de conteúdo (refutação de antigos erros, descoberta de novas verdades), e nem mesmo de uma alteração da forma teórica (renovação de paradigma, modificação dos conjuntos sistemáticos); o que está em questão é o que rege os enunciados e a maneira pela qual eles se regem uns aos outros para constituir um conjunto de proposições cientificamente aceitáveis pelo fato de serem verificadas ou infirmadas por procedimentos científicos (FOUCAULT, 2001b, p.143).
}

Quanto ao segundo eixo, trata-se do estudo das práticas não-discursivas, em linhas gerais concebidas enquanto tecnologias de poder, assim como as maneira através das quais elas se articulam com os saberes (as práticas discursivas). Este eixo não estava ausente em suas investigações arqueológicas, mas, quando presente, carregava uma concepção de poder 
marcadamente repressiva ${ }^{6}$. Através de uma maior aproximação com os trabalhos de Nietzsche, os quais resultaram no artigo "Nietzsche, a genealogia e a história" (de 1971), Foucault encontrou elementos que lhe permitiram conceber as práticas de poder não simplesmente enquanto formas de dominação e repressão, mas como um conjunto de estratégias globais e táticas locais, as quais apresentam um caráter eminentemente positivo ${ }^{7}$. Sua positividade é verificada pela investigação do modo como relações de força atuam sobre os corpos, não apenas impedindo-lhes ações ou comportamentos, mas de modo a recompensá-los, e procurar corrigi-los, fazer com que ações sejam realizadas de uma maneira específica e não de outra. Isto o levou a conceber que as relações de poder constituem corpos ao atravessar a sua própria espessura, e não apenas atuando do exterior sobre os mesmos. Ainda na entrevista de 1977, Foucault coloca:

\begin{abstract}
Quando se define os efeitos de poder pela repressão, dá-se uma concepção puramente jurídica deste mesmo poder; identifica-se o poder a uma lei que diz não; ele teria, sobretudo, a potência do interdito. Oras, eu creio que esta é uma concepção inteiramente negativa, estreita e esquelética do poder que foi curiosamente difundida. Se o poder fosse tão somente negativo, repressivo, se ele não fizesse nada além de dizer não, você acredita que nós realmente chegaríamos a obedecer-lhe? O que faz com que o poder se exerça efetivamente e que ele seja aceito, é simplesmente o fato que este não pesa somente como uma potência que diz não, mas que de fato ele atravessa, produz coisas, induz ao prazer, forma saber, ele produz discurso; é preciso considerá-lo como uma rede produtiva que passa através de todo o corpo social muito mais que como uma instância negativa que tem por função reprimir (FOUCAULT, 2001b, p.149).
\end{abstract}

Por fim, o terceiro eixo, referente às práticas ou técnicas de si já mencionadas, foi aberto a partir do momento em que Foucault se deparou com o desenvolvimento dos dispositivos de segurança social; com o papel exercido pelas ciências estatísticas no modo através do qual as instituições estatais atuavam; e com continuidades formais entre a confissão cristã e a confissão quando reapropriada por saberes e poderes laicos modernos (por exemplo, a psiquiatria, a criminologia, a pedagogia, e suas instituições). A partir de então, o filósofo francês passou a conceber as relações de poder não apenas enquanto relações de força, mas enquanto modos de condução de condutas, resumidos pelo termo governamentalidade ${ }^{8}$. Disso

\footnotetext{
6 Tal concepção negativa de poder pode ser facilmente encontrada nos procedimentos de "exclusão" e de "rarefação dos sujeitos que falam", parte da reflexão metodológica presente em "A Ordem do Discurso" (FOUCAULT, 2006a, pp.8-21; 36-45).

7 O estudo do sentido dos termos "proveniência" (Herkunft), e "emergência" (Entstehung) no referido artigo pode ser concebido como ponto de partida para a compreensão desta nova concepção de poder (FOUCAULT, 2007, pp.15-37).

8 A complexificação do estudo das relações de poder em direção às formas de governamentalidade está exposta entre as aulas de 11 de janeiro a 8 de fevereiro de 1978 (FOUCAULT, 2008). No entanto, pode haver um maior aprofundamento do estudo desta noção nos cursos que ainda não foram publicados: "Do governo dos vivos"
} 
seguiu-se um prolongamento da delimitação temporal de seus estudos, os quais incluem até a antiguidade grega. Ao estudar as práticas de si da antiguidade, Foucault se depara com efeitos do discurso verdadeiro sensivelmente diferentes daqueles que haviam sido objeto de suas pesquisas até então. Nosso artigo trata de um destes efeitos: a capacidade de a verdade transformar o modo de ser, o ethos daquele que tornava-se capaz de conhecer.

\section{Verdade e espiritualidade nos estudos de Foucault sobre as éticas da antiguidade}

Para entendermos melhor a especificidade da concepção de verdade contida nos estudos tardios de Foucault referentes às éticas da antiguidade ocidental, faz-se necessário adentrar nos cursos por ele ministrados. Encontramos em "Hermenêutica do sujeito", de 1982, elementos que ajudam a estabelecer tal especificidade. Concentramo-nos no momento em que Foucault localiza uma separação entre filosofia e espiritualidade a partir de suas investigações sobre o cuidado de si (epiméleia heautôu) e as articulações deste com o conhecimento de si (gnôthi seautón).

Neste curso, Foucault toma como fio condutor o cuidado de si, o qual apresenta-se como um dos principais elementos das técnicas de constituição de si mesmo características da Grécia clássica e do período imperial (séculos I e II d.C.). Cabe ressaltar que a noção de epiméleia heautồ apresenta uma longa duração permeada por mudanças de significação e pela associação com diferentes práticas ${ }^{9}$ :

parece-me que a noção de epiméleia beautoû acompanhou, enquadrou, fundou a necessidade de conhecer-se a si mesmo não apenas no momento de seu surgimento no pensamento, na existência, no personagem de Sócrates. Parece-me que a epiméleia heatôे (o cuidado de si e a regra que lhe era associada) não cessou de constituir um princípio fundamental para caracterizar a atitude filosófica ao longo de quase toda a cultura grega, helenística e romana (FOUCAULT, 2010a, p.10).

(1979-1980) e "Subjetividade e verdade" (1980-1981). Uma exposição aprofundada da concepção de governo é encontrada nos capítulos III e IV da obra de Candiotto (CANDIOTTO, 2010).

${ }_{9}^{9}$ Neste curso Foucault aponta e reitera diversas vezes os principais deslocamentos por que passa o princípio do cuidado de si entre a Grécia clássica e o período imperial. Em linhas gerais, trata-se de certa autonomização crescente do cuidado de si com relação ao governo dos outros e ao conhecimento de si. Mas o que nos interessa é mostrar algumas características do tipo de saber valorizado tanto no momento clássico quanto no helênico. Portanto, afastaremos nosso olhar de modo a evidenciar a diferença entre o saber da época antiga e o da época moderna. Para isso, tomaremos como contraste alguns pontos dos saberes modernos estudados por Foucault na década de 1970. 
Portanto, esta noção abrange, desde a filosofia da Grécia clássica até as escolas estóicas, epicurista e cínica. Finalmente o cuidado de si é também apropriado pelo cristianismo (Foucault encontra esse preceito nas obras de Gregório de Nissa e Basílio de Cesaréia, dentre outros). Ou seja, do século V a.C. ao IV-V d.C, temos por volta de mil anos de diferentes cuidados de si, uma vez que estão em jogo transformações em uma gama de práticas de subjetividade.

Foucault indaga sobre o motivo de o cuidado de si ter sido desconsiderado na reconstrução da história da filosofia ocidental em prol do conhecimento de si, do gnôthi seautón ${ }^{10}$. Este privilégio do conhecimento de si evidencia certo desconforto ou desconfiança da história contemporânea da filosofia com relação ao cuidado de si. A epiméleia heautồ se apresenta ao olhar contemporâneo como um elemento estranho, como se tratasse de

desafio e de bravata, uma vontade de ruptura ética, uma espécie de dandismo moral, afirmação-desafio de um estádio estético e individual intransponível. Ou então, soam aos nossos ouvidos como a expressão um pouco melancólica e triste de uma volta do indivíduo sobre si, incapaz de sustentar, perante seus olhos, entre suas mãos, por ele próprio, uma moral coletiva (a da cidade, por exemplo), e que, em face do deslocamento da moral coletiva, nada mais então teria senão ocupar-se consigo (FOUCAULT, 2010a, p.13) ${ }^{11}$.

No entanto, ocorre que desde Sócrates a Gregório de Nissa o cuidado de si foi um princípio que perpassou morais rigorosas, assumindo valor positivo; tratava-se de algo importante e valioso a ser feito, e não a única coisa que resta fazer diante de uma situação decadente. Da mesma maneira, as regras austeras das morais antigas que passavam pelo cuidado de si foram transferidas para o cristianismo e com isso foram novamente ressignificadas, deslocadas em seus objetivos e meios

para o interior de um contexto que é o de uma ética geral do não-egoísmo, seja sob a forma cristã de uma obrigação de renunciar a si, seja sob a forma 'moderna' de uma obrigação para com os outros, - quer o outro, quer a coletividade, quer a classe, quer a pátria, etc. Portanto, todos esses temas, todos esses códigos do rigor moral, nascidos que foram no interior daquela paisagem tão fortemente marcada pela obrigação de ocupar-se consigo

\footnotetext{
${ }^{10}$ Nesta caso trata-se da aula de 6 de janeiro de 1982, mas este tema é retomado em outros momentos do curso. 11 Como indicado na nota 47 do livro, trata-se de uma crítica a alguns helenistas como Bréhier e Festugière, no que diz respeito às suas respectivas interpretações do movimento de decadência da cidade e das relações políticas nos séculos I e II (já que não há mais polis democrática). Para tais estudiosos, o fim da cidade democrática teria sido responsável por um fechamento dos sujeitos sobre si mesmos, o qual seria evidenciado pelas formulações do cuidado de si. Pelo contrário, segundo a leitura de Michel Foucault e suas referências a outros helenistas como Peter Brown e Pierre Hadot, especialmente no período helênico, o cuidado de si implica em fortes relações sociais e não anula a política (FOUCAULT, 2010, p.23).
} 
mesmo, vieram a ser assentados pelo cristianismo e pelo mundo moderno a uma moral do não-egoísmo (FOUCAULT, 2010a, p.14).

O principal marco do esquecimento do cuidado de si, com seu respectivo recobrimento pelo conhecimento de si, é aquele que nosso autor chama de "momento cartesiano", o qual não inicia abruptamente com Descartes apenas, assim como não elimina absolutamente a questão da transformação do sujeito no próprio ato de conhecimento, a espiritualidade. Em linhas gerais, com as "Meditações", a evidência foi colocada na origem do procedimento da filosofia. Segundo Foucault, além da predominância do conhecimento de si sobre o cuidado, há uma significativa diferença entre o próprio conhecimento de si socrático e o conhecimento de si cartesiano. Tal diferença torna-se evidente quando Descartes possibilita o acesso ao conhecimento através da existência do sujeito enquanto tal:

colocando a evidência da existência própria do sujeito no princípio do acesso ao ser, era esse conhecimento de si mesmo (não mais sob a forma da prova da evidência mas sob a forma da indubitabilidade de minha existência como sujeito) que fazia do 'conhece-te a ti mesmo' um acesso fundamental à verdade (FOUCAULT, 2010a, p.15).

Então, para tratar do esquecimento do princípio do cuidado de si, Foucault delineia uma ruptura histórica entre filosofia e espiritualidade, a qual é cara para o recorte com o qual trabalhamos neste artigo $^{12}$. Se, por um lado a filosofia pode ser entendida como o pensamento que interroga o que faz com que seja possível o verdadeiro e o falso, o que permite que o sujeito tenha acesso à verdade e quais os limites desse acesso; por outro, a espiritualidade deve ser entendida como

o conjunto de buscas, práticas e experiências tais como as purificações, as asceses, as renúncias, as conversões do olhar, as modificações de existência, etc., que constituem, não para o conhecimento, mas para o sujeito, para o ser mesmo do sujeito, o preço a pagar para ter acesso à verdade (FOUCAULT, 2010a, p.15).

Desta maneira, a espiritualidade deixa patente o fato de que o sujeito não é de antemão capaz de acessar a verdade. Para que ele possa acessá-la, faz-se necessária uma transformação do sujeito em seu ser, a qual pode assumir a forma do Eros (quando a verdade vem ao sujeito arrancando-lhe de sua condição atual) ou da Áskesis (quando o sujeito realiza um trabalho contínuo sobre si mesmo em vista de transformar-se para ter acesso à verdade). Conforme as

${ }^{12}$ Foucault faz uma análise detida da estrutura do saber espiritual a partir de textos de Sêneca e Marco Aurélio nas aulas de 17 e 24 de fevereiro de 1982. 
palavras de Foucault, a espiritualidade coloca uma "necessidade de que o sujeito se modifique, se transforme, se desloque, torne-se, em certa medida e até certo ponto, outro que não ele mesmo, para ter direito ao acesso à verdade. A verdade só é dada ao sujeito a um preço que põe em jogo o ser mesmo do sujeito" (FOUCAULT, 2010a, p.16). Ou seja, a verdade só se dá conjuntamente à conversão ${ }^{13}$, à transformação do sujeito. A verdade retorna sobre o sujeito que conhece modificando-o, e com isso não pode ser reduzida à mera recompensa pelo ato de conhecimento:

Em suma, na verdade e no acesso à verdade, há alguma coisa que completa o próprio sujeito, que completa o ser mesmo do sujeito e que o transfigura. Resumindo, acho que podemos dizer o seguinte: para a espiritualidade, um ato de conhecimento, em si mesmo e por si mesmo, jamais conseguiria dar acesso à verdade se não fosse preparado, acompanhado, duplicado, consumado por certa transformação do sujeito, não do indivíduo, mas do próprio sujeito no seu ser de sujeito (FOUCAULT, 2010a, pp.15-16).

$\mathrm{Na}$ antiguidade clássica - com a exceção de Aristóteles -, assim como para as filosofas helênicas (estoicismo, epicurismo e cinismo), a filosofia não se separava da espiritualidade; o conhecimento implicava na transformação do sujeito que tornava-se capaz de conhecer. Assim, se tomarmos como referência de temporalidade a relação entre verdade e sujeito, a idade moderna inicia em um momento específico:

Creio que a idade moderna da história da verdade começa no momento em que o que permite aceder ao verdadeiro é o próprio conhecimento e somente ele. Isto é, no momento em que o filósofo (ou o sábio, ou simplesmente aquele que busca a verdade), sem que mais nada lhe seja solicitado, sem que seu ser de sujeito deva ser modificado ou alterado, é capaz, em si mesmo e unicamente por seus atos de conhecimento, de reconhecer a verdade e a ela ter acesso (FOUCAULT, 2010a, p.18).

Este seria o momento cartesiano, cuja consolidação traz uma conseqüência: agora, como a verdade é condicionada apenas pelo conhecimento, ela não traz qualquer outra recompensa que seu mero acúmulo. O que resta, então, é apenas o acúmulo de conhecimento sem qualquer transformação do sujeito que conhece. Foucault define ainda mais uma vez a diferença entre os dois momentos da história da verdade:

se definirmos a espiritualidade como o gênero de práticas que postulam que o sujeito, tal como ele é, não é capaz de verdade, mas que a verdade, tal

\footnotetext{
${ }^{13}$ Sobre o tema da conversão, ver as aulas de 3, 10 e 17 de fevereiro de 1982.
} 
como ela é, é capaz de transfigurar e salvar ${ }^{14}$ o sujeito, diremos então que a idade moderna das relações entre sujeito e verdade começa no dia em que postulamos que o sujeito, tal como ele é, é capaz de verdade, mas que a verdade, tal como ela é, não é capaz de salvar o sujeito (FOUCAULT, 2010a, p.19) ${ }^{15}$.

Porém, conforme apontado antes, tal desvinculação de forma alguma é abrupta e nem remete apenas a Descartes e Kant. Ela sequer é resultado da incipiência de um discurso científico entre o XVII e XVIII. Segundo nosso autor, o marco da separação está na teologia:

\begin{abstract}
A teologia (essa teologia que, justamente, pode fundar-se em Aristóteles confer o que lhes dizia há pouco - e que, com Santo Tomás, a escolástica, etc., ocupará na reflexão ocidental o lugar que conhecemos), ao adotar como reflexão racional fundante, a partir do cristianismo, é claro, uma fé cuja vocação é universal, fundava, ao mesmo tempo, o princípio de um sujeito cognoscente em geral, sujeito cognoscente que encontrava em Deus, a um tempo, seu modelo, seu ponto de realização absoluto, seu mais alto grau de perfeição e, simultaneamente, seu Criador, assim como, por conseqüência, seu modelo. A correspondência entre um Deus que tudo conhece e sujeitos capazes de conhecer, sob o amparo da fé é claro, constitui sem dúvida um dos principais elementos que fazem [fizeram] com que o pensamento - ou as principais formas de reflexão - ocidental e, em particular, o pensamento filosófico se tenham desprendido, liberado, separado das condições de espiritualidade que os haviam acompanhado até então, e cuja formulação mais geral era o princípio de epiméleia heautồ (FOUCAULT, 2010a, p.26).
\end{abstract}

Portanto, entre os séculos V e XVII, Foucault não encontra um conflito entre ciência e espiritualidade, mas entre teologia e espiritualidade; uma evidência desta separação pouco convencional está no fato de que a própria alquimia implicava na transformação do sujeito que a conhecia; portanto era um saber espiritual. Da mesma maneira, a reforma do conhecimento nos séculos XVI-XVII problematizou esta separação ${ }^{16}$.

\title{
3. Quadro geral da relação entre verdade e sujeito nas tecnologias de assujeitamento
}

\footnotetext{
${ }^{14}$ Sobre o tema da salvação, ver as aulas de 20 de janeiro e 3 de fevereiro de 1982.

15 No manuscrito do filósofo francês ainda consta o que seria a mais forte evidência da desvinculação entre espiritualidade e conhecimento, cuja demarcação poderia ser encontrada nas filosofias de Descartes e Kant: "quando Descartes disse que a filosofia sozinha se basta para o conhecimento, e quando Kant completou dizendo que, se o conhecimento tem limites, eles estão todos na estrutura do sujeito cognoscente, isto é, naquilo mesmo que permite o conhecimento" (FOUCAULT, 2010a, p. 25). Mas o fato de Foucault não ter feito tal afirmação durante a aula nos previne de considerá-la um diagnóstico do qual o filósofo francês não teria qualquer dúvida. A nota seguinte torna isso mais evidente.

${ }^{16}$ Posteriormente Foucault coloca que talvez nem mesmo em Kant todos os elementos da espiritualidade tenham desaparecido, assim como no XIX a questão sobre a necessidade de transformação do sujeito por ele próprio foi colocada indiretamente por outras filosofias como Schelling, Schopenhauer, Hegel, Nietzsche e Heidegger (FOUCAULT, 2010a, p.27).
} 
Como pudemos notar, o recorte proposto por Foucault mostra-nos uma vinculação entre verdade e subjetividade significativamente diferente quando comparada com aquela referente aos dispositivos de sujeição modernos estudados na década de 1970. Não se trata nem da mesma verdade e nem do mesmo tipo de subjetividade em ambos os casos. Para melhor contrastar esta mudança, apresentamos breve e pontualmente alguns elementos da relação poder-saber nos estudos genealógicos.

Seis anos antes das aulas que citamos, no curso "Em defesa da sociedade" (ano de 1976), a verdade que Foucault investigava era produzida na articulação com poderes, concomitantemente à produção de sujeitos: "Não há exercício do poder sem uma certa economia dos discursos de verdade que funcionam nesse poder, a partir e através dele. Somos submetidos pelo poder à produção da verdade e só podemos exercer o poder mediante a produção da verdade" (FOUCAULT, 2000, pp.28-29). Neste período de seus estudos, nosso autor contornava as teorias políticas focadas na formação jurídico-contratual do Estado, até então concebida através da fundamentação na soberania, legitimidade e contrato social. Para efetuar este contorno, Foucault partiu do estudo não do centro do poder, mas das suas extremidades, principalmente das práticas e técnicas lá utilizadas. Neste momento o filósofo francês construía sua concepção de poder positiva, construída através do estudo de uma miríade de técnicas de divisão do tempo e do espaço vindas da vida monástica, laicizadas entre os século XVII e a modernidade, as quais atuam diretamente sobre os corpos. O estudo destas técnicas, aliado à uma maior aproximação com a filosofia de Nietzsche, permitiu a construção de uma concepção de poder segundo a qual este não é detido por alguns (não é da ordem da propriedade ou mercadoria), mas circula por todo o corpo social fazendo aparecer efeitos globais de dominação.

Estes poderes atuam articulando-se com saberes, modificando-os e, principalmente produzindo-os. Conforme as palavras do filósofo francês:

(...) na base, no ponto em que terminam as redes de poder, o que se forma, não acho que sejam ideologias. É muito menos e, acho eu, muito mais. São instrumentos efetivos de formação e de acúmulo de saber, são métodos de observação, técnicas de registro, procedimentos de investigação e de pesquisa, são aparelhos de verificação. Isto quer dizer que o poder, quando se exerce em seus mecanismos finos, não pode fazê-lo sem a formação, a organização e sem pôr em circulação um saber, ou melhor, aparelhos de saber que não são acompanhamentos ou edifícios ideológicos (FOUCAULT, 2000, p.40). 
Trata-se de tecnologias de poder que produzem verdades, assim como trata-se de uma concepção de verdade identificada como norma, a qual produz heteronomamente sujeitos assujeitados. Devemos caracterizar tal verdade-norma de modo significativamente diferente da figura da verdade espiritual investigada na década de 1980 . Na modernidade ${ }^{17}$ a verdade é a norma:

Temos de produzir a verdade como, afinal de contas, temos de produzir riquezas, e temos de produzir a verdade para poder produzir riquezas. E, de outro lado, somos igualmente submetidos à verdade, no sentido de que a verdade é a norma; é o discurso verdadeiro que, ao menos em parte, decide; ele veicula, ele próprio propulsa efeitos de poder. Afinal de contas somos julgados, condenados, classificados, obrigados a tarefas, destinados a uma certa maneira de viver ou a uma certa maneira de morrer, em função de discursos verdadeiros, que trazem consigo efeitos específicos de poder (FOUCAULT, 2000, p.29).

Como dissemos anteriormente, o sujeito é produzido neste campo de imanência formado pelas tecnologias de poder e de saber (imanência porque não há uma esfera que determine absolutamente a outra; ambas implicam-se mutuamente). Esta produção heterônoma do sujeito torna-se clara quando o filósofo francês aponta o caráter de assujeitamento de tais tecnologias:

Não se deve, acho eu, conceber o indivíduo como uma espécie de núcleo elementar, átomo primitivo, matéria múltipla e muda na qual viria aplicar-se, contra a qual viria bater o poder, que submeteria os indivíduos ou os quebrantaria. $\mathrm{Na}$ realidade, o que faz que um corpo, gestos, discursos, desejos, sejam identificados e constituídos como indivíduos, é precisamente isso um dos efeitos primeiros do poder. Quer dizer, o indivíduo não é o visà-vis do poder; é, acho eu, um dos seus efeitos primeiros. O indivíduo é um efeito do poder e é, ao mesmo tempo, na mesma medida em que é um efeito seu, seu intermediário: o poder transita pelo indivíduo que ele constituiu (FOUCAULT, 2000, p.35).

No caso da aula mencionada trata-se do poder disciplinar, mas de acordo com nosso enfoque, também poderia tratar-se do biopoder, uma vez que, de acordo com o recorte do presente artigo, o que ressaltamos é o caráter produtivo e heterônomo destas tecnologias de assujeitamento. Certamente as tecnologias disciplinares são relativamente heterogêneas àquelas que constituem a biopolítica; são diferentes quanto ao seu objeto (corpo-máquina e corpo-

\footnotetext{
${ }^{17}$ Se admitirmos a divisão temporal traçada por Foucault na aula de 6 de janeiro de 1982, devemos destacar que neste trecho de 1976 tratar-se-ia de um momento específico dentro do grande período cartesiano, muito tempo após o predomínio da teologia sobre a espiritualidade. Seria um grande anacronismo pensarmos em norma ou tecnologias de normalização para nos referirmos, por exemplo, ao medievo.
} 
vivo), seus efeitos (de um lado trata-se da produção de corpos individualizados, produtivos e dóceis, e de outro, da regulação dos fenômenos biológicos de média e grande escala em uma população) e suas respectivas temporalidades (séculos XVII-XVIII e séculos XVIII-XIX-XX). Mas tal separação é relativa na medida em que, na maioria dos casos, ambas as tecnologias estão articuladas, como acontece no dispositivo da sexualidade exposto em $A$ vontade de saber (FOUCAULT, 2010). Numa entrevista de 1977 com o sugestivo título "Les rapports de powvoir passent à l'intérieur des corps" podemos encontrar precisamente esta relação entre poder, sujeito e, acrescentamos o termo saber sob nossa responsabilidade:

O que eu procuro fazer é tentar mostrar como as relações de poder podem passar materialmente pela própria espessura dos corpos sem precisarem ser remetidas para as representações dos sujeitos. Se o poder atinge o corpo, isso não ocorre porque ele foi inicialmente interiorizado na consciência das pessoas. Existe uma rede de biopoder, de somato-poder que é ela mesma a rede a partir da qual nasceu a sexualidade como fenômeno histórico e cultural no interior do qual por vezes nos reconhecemos, por vezes nos perdemos (FOUCAULT, 2001a, p.231).

Tomemos um último exemplo da relação poder-saber-sujeito nos estudos dos anos 70 . Trata-se do excurso metodológico contido em $A$ vontade de saber. Para a construção de uma história da extração da verdade e de um discurso sobre o sexo atravessado por relações de poder, Foucault distingue algumas prescrições relativas a seu método de investigação (regra da imanência; regra das variações contínuas; regra do duplo condicionamento; regra da polivalência tática dos discursos). De acordo com a regra da imanência, não há como fazer referência a uma sexualidade livre ou verdadeira esperando para ser descoberta por um conhecimento científico livre de preconceitos. "Se a sexualidade se constituiu como domínio a conhecer, foi a partir de relações de poder que a instituíram como objeto possível; e em troca, se o poder pôde chamá-la como alvo, foi porque se tornou possível investir sobre ela através de técnicas de saber e de procedimentos discursivos" (FOUCAULT, 2010b, pp.102-103). Esta produção da sexualidade aponta para o fato de que não encontramos, "entre técnicas de saber e estratégias de poder, nenhuma exterioridade; mesmo que cada uma tenha seu papel específico e que se articulem entre si a partir de suas diferenças" (FOUCAULT, 2010b, p.103). Quanto à regra das variações contínuas, esta implica em não procurar quem detém o saber ou o poder "mas, ao contrário, buscar o esquema das modificações que as correlações de força implicam através de seu próprio jogo" (FOUCAULT, 2010b, p.109). A regra do duplo condicionamento apresenta que entre as estratégias globais e as táticas locais não há homogeneidade (com variação apenas de escala) e nem heterogeneidade (em relação às partes), 
mas "deve-se pensar em duplo condicionamento, de uma estratégia, através da especificidade das táticas possíveis e, das táticas, pelo invólucro estratégico que as faz funcionar" (FOUCAULT, 2010b, p.110). A regra da polivalência tática dos discursos, que se nos apresenta como uma implicação da regra da imanência, traça outro ponto referente à forma com que Foucault estuda as relações de poder: o discurso não é meramente um lugar de expressão de um poder; ambos articulam-se e implicam-se mutuamente em sua imanência.

O que se diz sobre o sexo não deve ser analisado como a simples tela de projeção desses mecanismos de poder. É justamente no discurso que vêm a se articular poder e saber. E, por essa mesma razão, deve-se conceber o discurso como uma série de segmentos descontínuos, cuja função tática não é uniforme nem estável (FOUCAULT, 2010b, p.111).

Isso implica na recusa da divisão entre discurso dominante e dominado; o que aparece em seu lugar é uma miríade de discursos que podem entrar em diferentes estratégias globais e táticas locais:

É preciso admitir um jogo complexo e instável em que o discurso pode ser, ao mesmo tempo, instrumento e efeito de poder, e também obstáculo, escora, ponto de resistência e ponto de partida de uma estratégia oposta. $\mathrm{O}$ discurso veicula e produz poder; reforça-o mas também o mina, expõe, debilita e permite barrá-lo (FOUCAULT, 2010b, pp.111-112).

\section{Exemplo da vinculação entre verdade e espiritualidade em Demétrius}

Para finalizar este artigo, apresentamos um exemplo específico da relação entre verdade e sujeito nos estudos sobre a ética clássica e helênica. Com isso esperamos deixar claro o contraste do que viria a ser a relação entre o discurso verdadeiro e a produção de sujeitos durante as pesquisas da década de 1980.

$\mathrm{Na}$ aula de 10 de fevereiro de 1982, Foucault se debruça sobre o significado, nas filosofias helênicas, da conversão do olhar sobre as coisas do mundo para si mesmo ${ }^{18}$. Este

\footnotetext{
${ }^{18} \mathrm{Na}$ primeira hora da aula do mesmo dia, Foucault investigou como as filosofias clássicas e helênica traziam cada uma delas diferentes noções de conversão a si mesmo. Os estudos de Pierre Hadot apontavam para uma diferença entre a epistrophé platônica e a metánoia cristã na medida em que a primeira implicava numa conversão do olhar para o que há de divino na própria alma, enquanto que na segunda tratava-se de uma renovação radical da alma; renovação que, para ser atingida, fazia-se necessário passar obrigatoriamente por processos de mortificação e renúncia a si que não estavam presentes em Platão. Foucault encontrou nas filosofias dos séculos I e II um modelo intermediário onde o princípio de conversão significa que o sujeito mantenha-se no caminho correto, concentrando-se apenas em si mesmo, sem com isso remeter a um processo de conhecimento de si e do divino presente em si, como era o caso platônico, e sem implicar na anulação e renovação radical de si como no caso cristão.
} 
assunto diz respeito a um ponto central de seus estudos neste período: "como se estabelece, como se fixa e se define a relação entre o dizer-verdadeiro (a veridicção) e a prática do sujeito? Ou ainda de modo mais geral: como o dizer-verdadeiro e o governar ${ }^{19}$ (a si mesmo e aos outros) se vinculam um ao outro?” (FOUCAULT, 2010a, p.205). Mais especificamente, nosso autor quer colocar esta questão dentro do que ele entende por

quadro da constituição de uma relação de si para consigo, a fim de mostrar como se formou nessa relação um certo tipo de experiência de si que, parece-me, é característica da experiência ocidental, da experiência ocidental do sujeito por ele mesmo, mas igualmente da experiência ocidental que o sujeito pode ter ou fazer em relação aos outros (FOUCAULT, 2010a, pp.205-206).

O exemplo trazido é o de Demétruis, filósofo cínico aclimatado à aristocracia romana, freqüentemente citado por Sêneca ${ }^{20}$. Pelas citações deste texto, Foucault desconfia da divisão entre conhecimentos do mundo e conhecimentos do homem, onde o que interessaria à filosofia antiga seria precisamente o último, entendido como conjunto de conhecimentos que dizem respeito estritamente à esfera do humano, e não, por exemplo, à natureza. De acordo com o cínico, o filósofo deve tomar como modelo o atleta, o qual treina à exaustão apenas os movimentos essenciais para a luta, deixando de lado as acrobacias que para nada serviriam nesta situação. Da mesma forma, Demétrius separa o que deve ser conhecido daquilo que não o merece, a partir de um critério de utilidade (o qual irá remeter a outro critério investigado ainda nesta aula, do qual trataremos logo em seguida. Por enquanto, aceitemos tratar-se do critério de utilidade). Foucault encontra no texto sentenças que defendem que tudo o que está fora de nosso alcance é completamente inútil de ser conhecido:

(...). Nada perderás negligenciando coisas cujo conhecimento nos é interditado e inútil. A obscura verdade se oculta em um abismo. E não podemos acusar a malevolência da natureza. Porquanto nela nada é difícil de descobrir senão as coisas cuja descoberta só tem por fruto a própria descoberta. Tudo o que nos pode fazer melhores ou felizes, ela pôs sob nossos olhos e ao nosso alcance (SÊNECA apud FOUCAULT, 2010a, p.208).

\footnotetext{
19 O estudo da noção de governo a partir de 1978 com o curso "Segurança, território, população" se apresenta como um importante ponto de inflexão e extensão das pesquisas de Michel Foucault. Por governo é entendido o conjunto de técnicas de condução de condutas, no sentido material e espiritual, muito além do sentido administrativo-territorial de um Estado (mas incluindo este sentido). O rastreamento deste termo em textos que vão desde manuais técnicos de governo do século XVI, até regras monásticas dos primeiros séculos do cristianismo e em textos da filosofia clássica, levou Foucault a indagar sobre as articulações e transformações históricas da relação entre governo de si e governo dos outros (ORTEGA, 1999); (DUARTE, 2011); (CANDIOT'TO, 2010).

${ }^{20} \mathrm{O}$ texto de Demétrius na verdade só é conhecido através das citações de Sêneca.
} 
Dentre os conhecimentos inúteis estão muitos que dizem respeito aos homens, como as mudanças pelas quais se passa com o tempo (o ritmo da nova fase a cada sete anos de vida), as ilusões de ótica que remetem aos erros humanos, o paradoxo dos gêmeos (que nascem sob o mesmo signo mas tomam rumos diferentes em suas vidas). Desta maneira, o texto não traça uma oposição entre conhecimento das coisas do mundo e distantes de si, de um lado, e conhecimento de si e do que estaria nos recônditos de si, de outro. O corte é estabelecido a partir de outros critérios. Segundo Foucault, o traço comum de todos os conhecimentos tidos como inúteis, é o fato destes remeterem às causas; portanto, é tomado como inútil o conhecimento das causas ocultadas pela natureza (FOUCAULT, 2010a, p.209). Conhecer as causas ocultas é possível, e não envolve nenhuma transgressão, porém não é necessário; aqui serve o paralelo com o atleta, que pode conhecer muitas acrobacias as quais nunca serão usadas numa situação de luta. O conhecimento das causas é tão dispensável quanto complexas acrobacias numa luta.

Por outro lado, o que se deve conhecer resume-se a algumas noções gerais:

Que há pouco a temer dos deuses, que a morte não produz nenhum mal, que é fácil achar o caminho [da] virtude, que é preciso considerar-se como um ser social nascido para a comunidade. Enfim, saber que o mundo é um habitat comum, onde todos os homens estão reunidos para justamente constituir essa comunidade (FOUCAULT, 2010a, pp.209-210).

O que chama a atenção de Foucault, neste caso, é o fato deste tipo de conhecimento não remeter aos arcanos da consciência; não se trata de desviar o olhar do mundo exterior para dirigi-lo ao mundo interior, como no caso da espiritualidade cristã. Trata-se então de outra modalidade de saber, da qual Foucault destaca duas características: o fato de ser um saber relacional, e o fato deste remeter a princípios verdadeiros e imperativos em qualquer situação.

Quanto ao fato do caráter relacional dos saberes considerados úteis, Foucault destaca:

(...) porquanto o que agora há que se ter em conta quando consideramos os deuses, os outros homens, o kósmos, o mundo, etc., é a relação entre, por um lado, os deuses, os homens, o mundo, as coisas do mundo, e, por outro, nós. Fazendo de nós mesmos o termo recorrente e constante de todas essas relações, é que deveremos conduzir nosso olhar para as coisas do mundo, para os deuses e para os homens. É neste campo de relação entre todas as coisas e nós mesmos que o saber poderá e deverá desenvolver-se. Saber relacional: esta me parece ser a primeira característica do conhecimento que é validado por Demétrius (FOUCAULT, 2010a, p.210). 
Quanto à característica destes conhecimentos serem princípios passíveis de serem transcritos em prescrições, trata-se do fato destes serem "enunciados de verdade fundamental dos quais os outros podem ser deduzidos; e de que também se trata do enunciado de preceitos de condutas aos quais, em qualquer situação, há que submeter-se”. Mas Foucault ainda acrescenta uma terceira e principal - porque mais abrangente - característica a estes conhecimentos uma vez que eles são tais que "uma vez adquiridos, o modo de ser do sujeito se acha transformado, pois que é graças a isso que nos tornamos melhores, diz Demétrius" (FOUCAULT, 2010a, p.211). Desta maneira, nosso autor aponta que o caráter que define certos conhecimentos enquanto úteis ou inúteis não é seu conteúdo, mas sim sua capacidade de modificar o modo de ser do sujeito que passa a ser capaz de conhecer. Será recusado como inútil o conhecimento que não é capaz de proporcionar esta mudança, e,

em contrapartida será validado o modo de conhecimento que, considerando todas as coisas do mundo (os deuses, o kósmos, os outros, etc.) relativamente a nós, de pronto poderemos transcrever em prescrições, e elas modificarão o que somos, modificarão o estado do sujeito que conhece (FOUCAULT, 2010a, p.211).

Trata-se do tema da capacidade etopoética ou não de um conhecimento. Este tema, segundo nosso autor, perpassa não só a escola cínica, mas também a estóica e epicurista. Em todas estas escolas filosóficas helênicas e romanas, o conhecimento não se divide entre conhecimento das coisas do mundo e conhecimento da natureza humana. Desta maneira, a distinção dos conhecimentos não é traçada propriamente por seus respectivos conteúdos: "a distinção está no modo do saber e na maneira como aquilo que conhecemos sobre os deuses, os homens, o mundo, poderá ter efeito na natureza do sujeito, ou melhor dizendo, na sua maneira de agir, no seu êthos" (FOUCAULT, 2010a, pp.211-212). Assim, o critério de separação é menos a utilidade que a capacidade etopoética de um conhecimento. Desta maneira ainda estamos longe da modalidade cristã do conhecimento, onde este é entendido como conhecimento dos arcanos da consciência, e para o qual é necessária uma hermenêutica de si - o que dissolveria seu caráter relacional. No caso das filosofias helênicas dos séculos I e II d.C., "o conhecimento útil, o conhecimento em que a existência humana está em questão, é um modo de conhecimento relacional, a um tempo assertivo e prescritivo, e capaz de produzir uma mudança no modo de ser do sujeito" (FOUCAULT, 2010a,p. 212).

Reencontramos então o caso do saber espiritual. O conhecimento etopoético, isto é, aquele capaz de transformar o êthos daquele que conhece, apresenta-se como um tipo de saber capaz de modificar o ser do sujeito de modo a torná-lo outro com relação ao que era antes. 
Em outras palavras, no caso das filosofias greco-helênicas, o indivíduo torna-se capaz de conhecer constituindo-se a si mesmo como sujeito de ações corretas; ele não possui de antemão um núcleo originário que o dotaria desta capacidade ${ }^{21}$. Para finalizar este artigo, destacamos o ponto que reforça a principal característica desta relação entre verdade e subjetividade nas filosofias greco-helênicas estudadas por Foucault. De certa maneira, poderíamos objetar que os dispositivos modernos de sujeição também alteram os sujeitos que estes produzem, embora esta questão não faça parte dos estudos de Foucault nos anos 70. No entanto, diferentemente dos saberes modernos, o conhecimento espiritual dota o sujeito de uma capacidade autoconstitutiva cujos indícios são explícitos nas constantes metáforas que remetem à auto-finalização do eu encontradas nos textos estudados por Foucault ${ }^{22}$. Nestes, são recorrentes os exemplos de exortações à necessidade de desviar o olhar do mundo para fazê-lo voltar para si mesmo. Neste contexto, a imagem do pião aparece como exemplo negativo na medida em que este "gira sobre si, mas gira sobre si justamente como não convém que giremos sobre nós. O que é o pião? É alguma coisa que gira sobre si por solicitação e sob o impulso de um movimento exterior” (FOUCAULT, 2010a, p.186). Da mesma maneira, este objeto apresenta uma de suas faces para cada posição que lhe é exterior, assim como parece estar parado quando na realidade está em movimento. Trata-se do estado inverso daquele preconizado por tais filosofias:

Ora, contrariamente ao movimento do pião, a sabedoria consistirá em não se deixar jamais ser induzido a um movimento involuntário por solicitação e impulso de um movimento exterior. Pelo contrário, será preciso buscar no centro de nós mesmos o ponto no qual nos fixaremos e em relação ao qual permaneceremos imóveis (FOUCAULT, 2010a, pp.186-187).

Se deslocássemos experimentalmente esta metáfora para os dispositivos de sujeição modernos estudados por Foucault, poderíamos comparar os sujeitos produzidos pelos mesmos com a imagem do pião, cujo movimento é induzido por instâncias que lhes são alheias. Em linhas gerais, do lado moderno temos a heteronomia como modo da relação entre verdade e sujeito; enquanto que do lado da antiguidade temos a autonomia, ou seja, saberes que carregam princípios gerais dentro dos quais os indivíduos se mobilizam de acordo com as circunstâncias, e que dotam estes indivíduos de uma capacidade autoprodutiva quanto àquilo que diz respeito a seus êthos.

\footnotetext{
${ }^{21}$ O caso da análise da stultitia em Sêneca, tratado na aula de 27 de janeiro de 1982 é emblemático como exemplo desta capacidade de subjetivação do discurso verdadeiro.

${ }^{22}$ Trata-se da aula de 10 de fevereiro de 1982, na qual Foucault se remete aos estudos do helenista André-Jean Festugière, especialmente a seu livro Hermétisme et mystique païenne.
} 
Estes são alguns elementos que fazem com que a figura do si não seja indício de um retorno ao sujeito nos anos 80 , e "se em seus últimos trabalhos Foucault fala do sujeito, não se trata do sujeito epistêmico ou genealógico, mas de um sujeito ético, constituído através de práticas de si” (ORTEGA, 1999, p.45), as quais são elas também variáveis histórica e geograficamente. Por motivos heurísticos, podemos dizer que nos estudos das práticas de si Foucault trata de subjetividades, e não de um sujeito. Acreditamos ser possível avançar ainda mais na definição do estatuto de tal subjetividade constituída a partir das práticas de si ao colocá-la não enquanto constituída, e nem constituinte (ORTEGA, 1999, p.63), mas no gerúndio reflexivo: constituindo-se. Assim indicamos melhor a dobra sobre si e o inacabamento que caracterizam a subjetividade, em detrimento dos atributos de fixidez, unidade e identidade da noção de sujeito, uma vez que não há finalização no trabalho exercido sobre $\operatorname{si}^{23}$ (FOUCAULT, 2010a, p.79). Da mesma maneira, acreditamos que nos trabalhos da década de 1980, Foucault aponta para relações entre verdade e subjetividade onde as verdades dotavam os indivíduos de uma capacidade de produção de si mesmo, de modo a conferir-lhes autonomia e, desta maneira, tornarem-se radicalmente diferentes de seu estado anterior. Tratase então de uma relação entre verdade e sujeito significativamente distinta daquelas presentes nos dispositivos modernos de sujeição, produtores de sujeitos assujeitados. Acreditamos que o novo elemento político que aparece na filosofia de Foucault neste momento é o de pensar e alargar os espaços de autoconstituição na contemporaneidade.

\section{Implicações políticas contemporâneas dos estudos de Foucault sobre a ética antiga}

Finalizamos o presente artigo apontando para um exemplo da contemporaneidade política das investigações de Foucault nos anos 80. Seu trabalho com os antigos não nos parece nem pura erudição, nem a procura, nos gregos, da solução para o enfrentamento às tecnologias de poder totalizadoras e individualizadoras de nossa época, descritas na conferência Omnes et Singulatim, de 1981. Foucault deixa claro na entrevista "A propósito da genealogia da ética", de 1983: "Não, eu não procuro por uma solução de rechange $e^{24}$; não se

\footnotetext{
23 Esta impossibilidade de o cuidado de si chegar a um fim acabado restringi-se às filosofias helênicas, uma vez que na Grécia clássica o cuidado de si é definido como conhecimento da alma sobre si mesma o qual deve ser exercido numa época delimitada da existência: o período imediatamente anterior àquele onde o indivíduo torna-se cidadão. Esta diferenciação está exposta na aula de 20 de janeiro de 1982.

${ }^{24}$ A tradução dos originais em francês é de nossa responsabilidade. Decidimos manter o termo "rechange" no original por ele ser difícil de traduzir, apesar de seu sentido ser simples. O prefixo " $r e$ " diz respeito a um estado
} 
encontra a solução de um problema na solução de outro problema colocado em outra época por pessoas diferentes" (FOUCAULT, 2001b, p.1205). No entanto, se Foucault repudia qualquer retorno contemporâneo aos antigos, suas pesquisas desenvolvidas com tal recorte cronológico-temático são capazes de deslocar certas problematizações políticas contemporâneas ao construir novas perspectivas da relação entre passado e presente. Ao estudar os antigos, nosso autor não deixa de lado sua preocupação com a contemporaneidade; por exemplo: ao encontrar nos primeiros uma figura esquecida da verdade enquanto capaz de transformar aquele que passa a ter acesso a ela, Foucault delimita a singularidade histórica da maneira como nossa época se relaciona com a verdade, ao mesmo tempo em que abre fissuras que tornam possíveis transformações desta condição. $\mathrm{Na}$ entrevista "O sujeito e o poder" (entrevista de 1982, mesmo ano em que ministrou o curso com o qual trabalhamos), Foucault separa três tipos de lutas políticas. De um lado as lutas contra a dominação étnica, social e religiosa, de outro as lutas contra a exploração que separa o indivíduo do que ele produz, e de outro as lutas que combatem os mecanismos que ligam o indivíduo a ele mesmo e, desta maneira, assegura sua submissão aos outros. Estes três tipos de lutas nunca se dão separadamente, embora em determinados momentos históricos um deles se destaque. No feudalismo prevalece o primeiro tipo, no capitalismo do XIX prevalece o segundo, e na contemporaneidade, prevaleceria o terceiro tipo, embora os outros dois não tenham de forma alguma desaparecido, mas antes articularam-se ao último tipo. Sobre esta última modalidade de lutas são destacadas seis características: em primeiro lugar, são transversais na medida em que não se restringem a apenas um país; em segundo, dirigem-se contra os efeitos de poder de certos saberes (como, por exemplo, o poder que exerce o saber médico sobre o corpo, a vida e a morte das pessoas); em terceiro, são lutas imediatas na medida em que são direcionadas às instâncias de poderes que estão mais próximas de cada caso específico; em quarto, elas colocam em questão o estatuto do indivíduo:

de um lado elas afirmam o direito à diferença e ressaltam tudo o que pode tornar os indivíduos realmente individuais. De outro, elas atacam tudo o que pode isolar o indivíduo, cortar suas relações com outros, cindir a vida comunitária, constranger o indivíduo a se redobrar sobre si mesmo e o atrelar à sua identidade própria (FOUCAULT, 2001b, pp.1045-1046).

Em quinto, elas opõem resistências aos efeitos de poder que são ligados aos saberes, não para com isso desenvolver um saber que seja livre de efeitos de poder, e nem em nome de

de coisas anterior ao atual, enquanto o substantivo "changement" significa mudança. Logo, rechange nada mais é que trazer de volta um estado de coisas do passado, e que no caso se refere à ética greco-romana. 
uma relativização do conhecimento, mas sim para colocar em questão a maneira como os saberes circulam e se articulam às tecnologias de poder; em sexto, elas questionam a violência exercida pelo Estado que ignora quem somos individualmente, assim como as investigações científicas ou administrativas que determinam nossas identidades.

Resumidamente, as lutas políticas contemporâneas se constroem contra um tipo de poder específico:

\begin{abstract}
que se exerce na vida cotidiana e imediata das pessoas, que classifica os indivíduos em categorias, designa-os por sua individualidade própria, lhes fixa em suas identidades, lhes impõem uma lei de verdade a qual eles devem reconhecer em si mesmos e que os outros devem reconhecer neles. Trata-se de uma forma de poder que transforma os indivíduos em sujeitos. Há dois sentidos para a palavra 'sujeito': sujeito submetido a outro pelo controle e pela dependência, e sujeito vinculado à sua própria identidade pela consciência ou conhecimento de si. Nos dois casos, essa palavra sugere uma forma de poder que subjuga e assujeita (FOUCAULT, 2001b, p. 1046).
\end{abstract}

Ou seja, na contemporaneidade as novas lutas se voltam contra a submissão éticopolítica de subjetividades. Estas novas lutas trazem consigo novos objetivos:

sem dúvida o objetivo principal hoje não é o de descobrir, mas de recusar o que nós somos. É necessário imaginarmos e construir aquilo que poderíamos ser para nos desvencilharmos dessa espécie de 'dupla constrição' política que é a individualização e a totalização simultâneas das estruturas do poder moderno (FOUCUAULT, 2001b, p.1051).

Contrariamente às lutas políticas pautadas pela organização partidária ou pela ótica de inclusão estatal, trata-se não mais de lutar por reconhecimento identitário, e nem pela realização e conquista de algo que já somos em estado latente e só não somos de fato porque seríamos reprimidos ou iludidos. Trata-se de abandonar as identidades que nos são conferidas e através das quais nos reconhecemos, para que nos diferenciemos de nós mesmos ${ }^{25}$. Desta forma, se na primeira aula de "Hermenêutica do sujeito" Foucault trata da vinculação entre verdade-filosofia e espiritualidade, nos sentimos compelidos, pela entrevista do mesmo ano, a abrir a possibilidade de indagarmos acerca das possíveis relações entre política e

\footnotetext{
${ }^{25}$ Faz-se necessária uma pequena observação quanto ao modo com que Foucault está tratando a possibilidade de resistência à sujeição de subjetividades nesta entrevista, e o modo como compreende a vinculação entre verdade e espiritualidade em seus estudos sobre a ética antiga. Na entrevista parece ser apontada a necessidade de um movimento de dessubjetivação, enquanto que em "Hermenêutica do Sujeito", nosso autor destaca que os discursos verdadeiros tinham a importância de constituírem o modo de ser daquele que tornava-se capaz de acessá-lo (FOUCAULT, 2010a, pp.291-292). Com isso, cabe levantarmos a questão mais geral sobre a possibilidade de todo movimento de subjetivação implicar também num movimento de dessubjetivação. No entanto, responder a tal questão implicaria num trabalho diferente do qual nos propusemos no momento.
} 
espiritualidade. Trata-se de interrogar em que medida a ação política poderia estar em estabelecer outro tipo de relação de nós para conosco e com os outros, abandonando as identidades que nos são conferidas pelas tecnologias de poder individualizadoras e totalizadoras; tratar-se-ia da política como possibilidade de experimentos éticos de constituição de subjetividades (a política como etopoética), para os quais os trabalhos de Foucault nos anos 80 apontam, contudo sem carregar com isso qualquer prescrição ou normatividade. 


\section{Referências Bibliográficas}

CANDIOTTO, César. Foucault e a crítica da verdade. Belo Horizonte; Curitiba: Autêntica; Champagnat, 2010.

DELEUZE, Gilles. Conversações. PELBART, Peter Pál (trad.). São Paulo: 34, 2009.

DUARTE, André. Vidas em Risco: crítica do presente em Heidegger, Arendt e Foucault. Rio de Janeiro: Forense Universitária, 2010.

FOUCAULT, Michel. A Ordem do Discurso. São Paulo: Edições Loyola, 2006a. . Em Defesa da Sociedade. São Paulo: Martins Fontes, 2000. Vigiar e punir. Petrópolis: Vozes, 2006b. Segurança, território, população. São Paulo: Martins Fontes, 2008. Hermenêutica do sujeito. São Paulo: Martins Fontes, 2010a. História da sexualidade: A vontade de saber. Rio de Janeiro: Graal, 2010b.

História da sexualidade: O uso dos prazeres. Rio de Janeiro: Graal, 2010c. Dits et écrits. Tome I. Paris: Gallimard, 2001a. Dits et écrits. Tome II. Paris: Gallimard, 2001b.

ORTEGA, Francisco. Amizade e estética da existência em Foucault. Rio de Janeiro: Graal, 1999. 